\title{
Do schoolbags cause back pain in children and adolescents? A systematic review
}

\author{
Tiê Parma Yamato, ${ }^{1,2,3}$ Chris G Maher, ${ }^{1,4}$ Adrian C Traeger, $^{1}$ Christopher M Wiliams, ${ }^{2,3,5}$ \\ Steve J Kamper ${ }^{1,3}$
}

- Additional material is published online only. To view please visit the journal online (http://dx.doi.org/10.1136/ bjsports-2017-098927).

${ }^{1}$ Institute for Musculoskeletal Health, Sydney Local Health District, The University of Sydney, Sydney, New South Wales, Australia ${ }^{2}$ Hunter New England Population Health, Hunter New England Local Health District, Wallsend, New South Wales, Australia

${ }^{3}$ Centre for Pain, Health and Lifestyle, Australia

${ }^{4}$ Institute for Musculoskeletal Health, The University of Sydney, Sydney, New South Wales, Australia

${ }^{5}$ School of Medicine and Public Health, Hunter Medical Research Institute, University of Newcastle, Newcastle, New South Wales, Australia

Correspondence to Dr Tiê Parma Yamato, Musculoskeletal Health Sydney, School of Public Health, Sydney Medical School, The University of Sydney, Sydney NSW 2050, Australia;

tie.yamato@sydney.edu.au

Accepted 20 February 2018 Published Online First

2 May 2018

Check for updates

To cite: Yamato $\mathrm{TP}_{\mathrm{,}}$ Maher CG, Traeger AC, et al. Br J Sports Med 2018:52:1-6.

\section{ABSTRACT}

Objective To investigate whether characteristics of schoolbag use are risk factors for back pain in children and adolescents.

Data sources Electronic searches of MEDLINE, EMBASE and CINAHL databases up to April 2016. Eligibility criteria for selecting studies Prospective cohort studies, cross-sectional and randomised controlled trials conducted with children or adolescents. The primary outcome was an episode of back pain and the secondary outcomes were an episode of care seeking and school absence due to back pain. We weighted evidence from longitudinal studies above that from cross-sectional. The risk of bias of the longitudinal studies was assessed by a modified version of the Quality in Prognosis Studies tool. Results We included 69 studies ( $n=72627)$, of which five were prospective longitudinal and 64 cross-sectional or retrospective. We found evidence from five prospective studies that schoolbag characteristics such as weight, design and carriage method do not increase the risk of developing back pain in children and adolescents. The included studies were at moderate to high risk of bias. Evidence from cross-sectional studies aligned with that from longitudinal studies (ie, there was no consistent pattern of association between schoolbag use or type and back pain). We were unable to pool results due to different variables and inconsistent results.

Summary/conclusion There is no convincing evidence that aspects of schoolbag use increase the risk of back pain in children and adolescents.

\section{INTRODUCTION}

Back pain is well known for its frequency and global burden. ${ }^{1}$ The mean point prevalence of low back pain (LBP) in adults is estimated as $18.3 \%$ and 1 -year prevalence is $38 \%,{ }^{1}$ while the 1 -year prevalence rates for mid-back pain range from $15 \%$ to $35 \% .^{2}$ Epidemiological data have shown that back pain is not only a health problem for adults but is also frequently reported by children and adolescents. $^{34}$ The prevalence of back pain reported by children and adolescents is high in many parts of the world, ${ }^{5}$ and prevalence increases rapidly with age through adolescence. ${ }^{6}$ A recent large multinational study reported that the self-reported prevalence of back pain was $27 \%, 37 \%$ and $47 \%$ among children aged 11, 13 and 15 years, respectively. Other studies found that by the age of 14-17 years, $11 \%-71 \%$ have experienced at least one episode of back pain. ${ }^{89}$

The aetiology of back pain in children and adolescents is unknown. Studies investigating risk factors for back pain in children and adolescents report mostly unclear associations. ${ }^{4}$ Some evidence suggests that psychosocial factors (eg, distress), female gender and smoking may increase the risk of back pain in this population. ${ }^{4}$ The evidence for anthropometric factors (eg, height, weight), posture and lifestyle factors is mixed and of generally poor quality. ${ }^{4}$ Although loading or biomechanical factors are frequently cited as causes for back pain in children and adolescents, the evidence is inconsistent. $^{4} 10$

Schoolbag characteristics are one biomechanical factor often implicated as a cause of back pain in children and adolescents. Despite the lack of convincing evidence, schoolbags have been traditionally linked to back pain in children and adolescents. ${ }^{11}$ Heightened awareness of this issue by the general public means that clinicians are frequently asked for advice on a preferred style of schoolbag and/or how to carry the schoolbag to reduce risk of back pain. ${ }^{12}$ More specifically, the attention on the magnitude of load carried by children and adolescents to and from school has been increasing.

To date, there is variation regarding recommendations for children and adolescents carrying schoolbags. ${ }^{13}$ Guidelines for safe loads are mostly within $10 \%-15 \%$ of body weight (BW) range but include values as low as $5 \%{ }^{14}$ and as high as $20 \% .{ }^{15}$ Some biomechanical studies suggest that the schoolbag weight of $10 \%$ of BW may be enough to cause changes in kinematics, body posture and muscular strain. ${ }^{16} 17$ The evidence investigating the association between schoolbag weight or other schoolbag characteristics and the risk of back pain is inconclusive and not helpful to determine any choice of limit or recommendations regarding schoolbags. ${ }^{4} 15$ A greater understanding of schoolbag-related risk factors for back pain is important to determine appropriate preventative action for children and adolescents. $^{18}$

The aim of this study is to investigate whether characteristics of schoolbag use (eg, weight, duration of use, bag design, method of carrying bag, perceived weight) are risk factors for back pain in children and adolescents.

\section{METHODS}

The protocol for this review was registered prospectively on International Prospective Register for Systematic Reviews (CRD 42016037689). This systematic review is reported according to the Meta-analysis Of Observational Studies in Epidemiology checklist. ${ }^{19}$ 


\section{Searches}

Systematic searches were conducted in MEDLINE, EMBASE and CINAHL from their inception until November 2017. The search strategy included spinal pain terms, terms related to children and adolescents and terms related to schoolbags; the search strategy was based on previous Cochrane reviews in relevant areas (online supplementary appendix 2). Additional strategies (eg, examination of reference lists and citation tracking of included studies) were used to identify further eligible studies. Searches were not limited by language; collaborators with the relevant language skills assessed studies published in languages other than English, Portuguese and Spanish.

\section{Study selection}

We included prospective longitudinal cohort studies, cross-sectional studies and randomised controlled trials (RCT) that studied back pain as the main outcome. Eligible studies needed to include children or adolescents of school age as participants and report information about 'carrying a backpack'. Two reviewers independently screened titles and abstracts and excluded irrelevant records. Full-text articles were assessed by two reviewers independently to identify studies that met the inclusion criteria. Any disagreement was resolved by consensus.

\section{Outcomes}

The primary outcome was an episode of back pain with no restriction for duration. We considered lumbosacral, lumbar and thoracic pain as 'back pain'. The secondary outcomes were an episode of care seeking for back pain (ie, one or more consultations with a healthcare provider for back pain) and an episode of school absence due to back pain. ${ }^{20}$

\section{Data extraction and risk of bias assessment}

All data were extracted by two reviewers independently. Where necessary, study authors were contacted by email in order to obtain additional information that was not reported in the articles. The following data were extracted from each study:

- study characteristics: source of patients, sample size, follow-up period and loss to follow-up;

- number of new episodes of back pain during study period (primary outcome);

- number of episodes of care seeking for back pain and episodes of school absence due to back pain (secondary outcomes);

- weight of schoolbag (absolute weight or expressed as the percentage of child's BW);

- other characteristics of schoolbag use (eg, duration of use, bag design, method of carrying bag, perceived weight);

- statistical measure to quantify association (eg, relative risk, OR, HR) and 95\% CI.

The risk of bias assessment of the longitudinal studies was assessed by a modified version of the Quality in Prognosis Studies (QUIPS) tool, which has been recommended by the Cochrane Prognosis Methods Group. The QUIPS was modified to judge bias in relation to risk factors, instead of the original tool's focus on prognostic factors. The following six domains were considered: (1) study participation, (2) study attrition, (3) measurement of risk factor, (4) measurement of, and controlling for confounding variables, (5) measurement of outcomes and (6) analysis and reporting. Each domain was assessed as having high, moderate or low risk of bias. The overall risk of bias was also assessed. We considered a study to be of high quality when the risk of bias was rated low on at least four of the six domains and was rated low for both study attrition and study confounding. Two reviewers assessed the risk of bias of the studies independently and discrepancies were resolved by consensus, if necessary, a third author helped to reach the consensus. We planned to incorporate risk of bias ratings into interpretation of findings by comparing results from studies at low risk of bias to those from the total pool of included studies.

\section{Data synthesis}

Longitudinal and cross-sectional designs were assessed separately. To analyse whether characteristics of schoolbag use are risk factors for back pain, the relationship between schoolbag characteristics and back pain was explored and pooled if adequate numbers of longitudinal studies examining similar risk factors were identified. For the cross-sectional studies, we performed a descriptive analysis to report the factors associated with back pain. We made the decision a priori to primarily base conclusions on findings from longitudinal studies because they offer a more robust design for making causal inferences. The decision as to whether to pool studies was made on the basis of clinical and methodological homogeneity; this involved subjective decision based on consensus among the authors. Key factors in this decision included measures of exposure and outcome, timing of data collection and reporting of analyses.

\section{RESULTS}

The searches retrieved 6597 studies. After removing duplicates and screening titles and abstracts, we included 160 studies for full-text assessments; we could not access the full-text for six of these studies and attempts to contact the authors were not successful. A total of 69 studies met our inclusion criteria and were included in this review (total $n=72627$ participants). We included four longitudinal cohort studies $(n=1743)$, one RCT $(n=108), 63$ cross-sectional studies $(n=70720)$ and one casecontrol with retrospective data $(n=56)$ (figure 1$)$. The characteristics of the prospective studies (longitudinal cohort and RCT) are described in table 1 , and the characteristics of the cross-sectional and case-control studies are described in the online supplementary appendix 1. It was not possible to pool data due to heterogeneity regarding exposure (backpack) and outcome (back pain) measures.

\section{Prospective studies}

The five prospective studies were judged as moderate to high risk of bias for most risk of bias domains from QUIPS (table 2). Two studies ${ }^{21} 22$ were rated as high risk of bias and three $e^{23-25}$ as moderate risk of bias. The domains of 'study attrition', 'prognostic factor measurement' and 'study confounding' were the most poorly described domains. The domain of 'outcome measurement' was the best described. Due to the high heterogeneity between included studies, we have presented results descriptively.

Two prospective studies (one longitudinal cohort ${ }^{23}$ and one $\mathrm{RCT}^{22}$ ) evaluated associations between schoolbag weight (\% BW) and risk of developing LBP; neither reported an association. Based on the QUIPS rating for these two studies, weighting by sample size, we consider this moderate quality evidence for no relationship between backpack weight and back pain.

Two longitudinal studies evaluated 'perception of schoolbag weight' and risk of LBP. One study ${ }^{21}$ found that children with back pain who reported difficulty carrying their schoolbag had increased in risk of developing persistent LBP (RR 2.1, 95\% CI 1.1 to 4.0$)$. Another study ${ }^{25}$ also reported an association between 


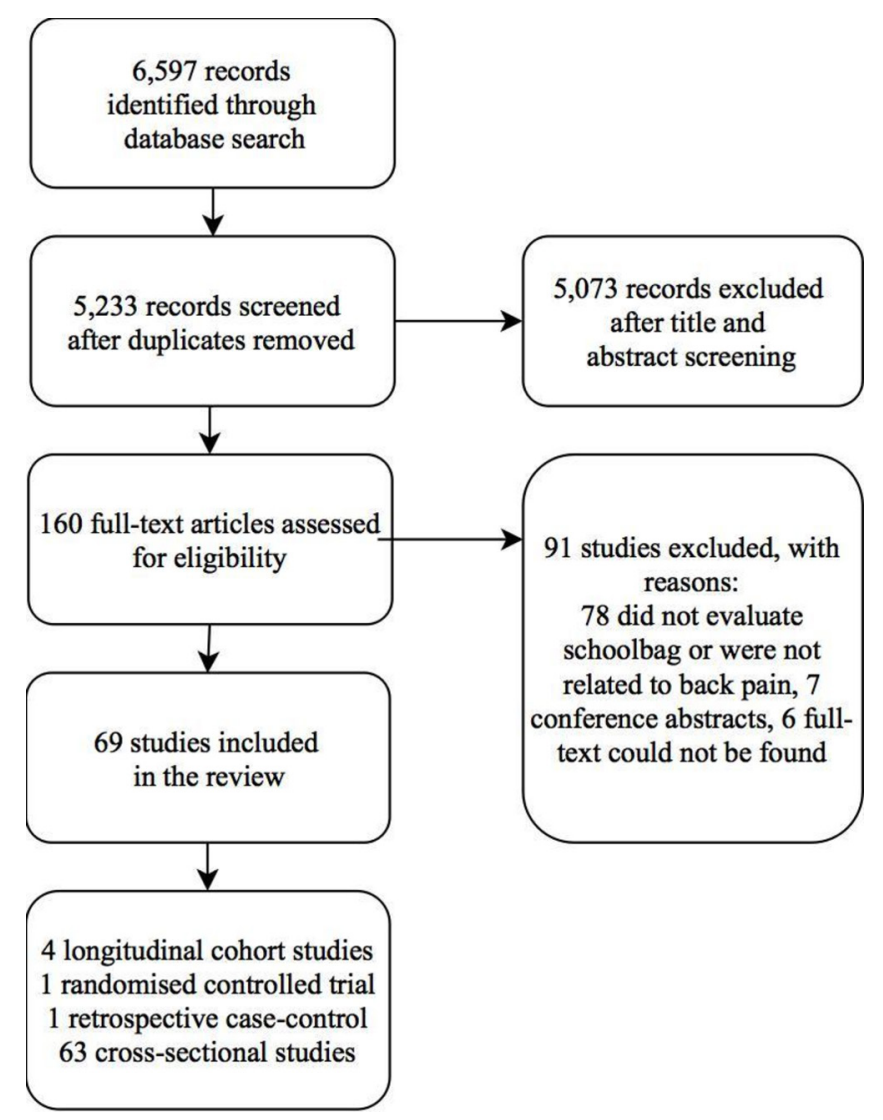

Figure 1 Flow chart of the included studies in this review.

the perception of schoolbag weight as heavy and LBP (OR 2.2, $95 \%$ CI 1.0 to 4.8). Based on the QUIPS rating for these two studies, we consider this low quality evidence for a relationship between perception of backpack weight and back pain.

Another longitudinal study ${ }^{24}$ did not investigate schoolbag weight or perception of weight; however, for the question on 'pain provoking situations', none of the participants mentioned that carrying the schoolbag provoked pain. None of the prospective longitudinal studies reported data on duration of using a schoolbag, episodes of care seeking for back pain or episodes of school absence due to back pain. The results from longitudinal studies are summarised in table 3 .

\section{Cross-sectional and case-control studies}

Twenty-eight studies investigated weight of schoolbag (\% BW), ranging from $5 \%$ to $19 \% \mathrm{BW}$, and 29 studies investigated load carried, which ranged from $2 \mathrm{~kg}$ to $10 \mathrm{~kg}$. Fourteen studies investigated duration of use of the schoolbag (ie, time carrying), ranging from 20 to 85 min per day. Regarding schoolbag design and method of carrying the bag, 22 studies reported that most students used backpacks or rucksacks (around 90\%) and carried the schoolbag on both shoulders (around 75\%), and a minority of students used satchels or shoulder bags carried on one shoulder or by hand.

Twenty-nine cross-sectional studies did not find an association between schoolbag characteristics and LBP. ${ }^{26-54}$ Four studies reported a positive association between the child's perception of backpack weight and back pain. ${ }^{55-58}$ Three studies reported associations between the duration of carrying a back pack (prolonged periods) and back pain. ${ }^{575960}$ Four studies reported associations between schoolbag weight (heavier) and back pain, ${ }^{60-63}$ and other three studies found an association between the method of

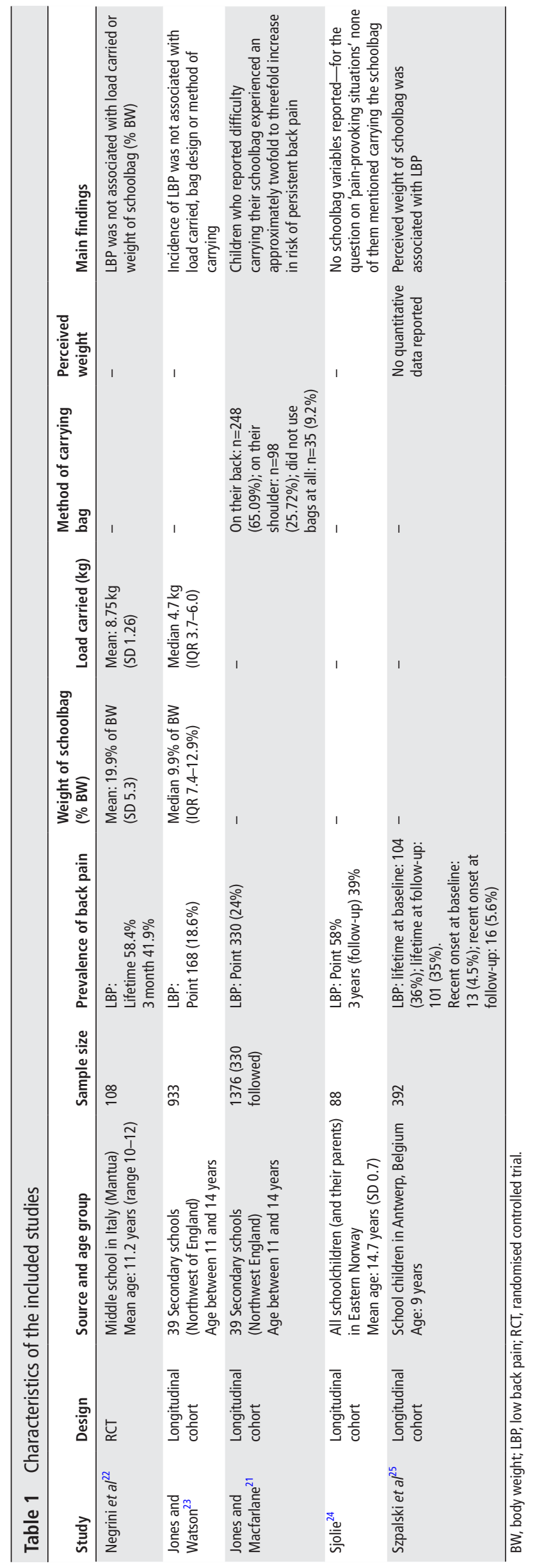


Table 2 Risk of bias assessment for the prospective studies

\begin{tabular}{lllllll}
\hline Study & Study participation & Study attrition & Prognostic factor & $\begin{array}{l}\text { Outcome } \\
\text { measurement }\end{array}$ & Study confounding & Statistical analysis and reporting \\
\hline Jones and Watson ${ }^{23}$ & Moderate & Moderate & Moderate & Low & Moderate & Moderate \\
Jones and Macfarlane $^{21}$ & High & High & High & Low & High & High \\
Sjolie $^{24}$ & Low & Moderate & High & Low & High & Moderate \\
Szpalski et $a l^{25}$ & Moderate & High & Moderate & Moderate & Moderate & Moderate \\
Negrini $e t ~ a l^{22} 2004$ & Moderate & High & High & High & High & High \\
\hline
\end{tabular}

carrying the schoolbags (one shoulder or asymmetrically) with back pain. ${ }^{426465}$ For the retrospective case-control study, there were no data regarding the schoolbag weight or features, but $75 \%$ of the subjects with chronic non-specific LBP reported that carrying a schoolbag aggravated their pain.

Episodes of care seeking for back pain were reported in 14 cross-sectional studies. ${ }^{27} 3035373842-44616466-69$ The prevalence of care seeking ranged from $1.6 \%$ to $35 \%$ (median 18.5 , IQR 8.6-23.3). However, none of the studies investigated the association between schoolbag use and care seeking for back pain. School absence due to back pain was reported in six cross-sectional studies, ${ }^{273038415561}$ with median prevalence of $7.8 \%$ of absence for one or more days (IQR 1.8-20.5). However, none of the studies investigated the association between schoolbag use and school absence due to back pain.

Because we anticipated different definitions of back pain episodes, we planned a sensitivity analysis to explore the influence of episode definition on risk. However, for the prospective studies, the definitions were all were very similar, so we did not perform this analysis.

\section{DISCUSSION}

This systematic review provides evidence from prospective studies with moderate to high risk of bias that schoolbag characteristics such as weight, design and carriage method do not increase the risk of developing back pain in children and adolescents. Two prospective studies reported that the perception of heaviness or difficulty in carrying the schoolbag were associated with back pain and persistent symptoms. Evidence from cross-sectional studies supported the findings from prospective studies. Taken together, these results are not suggestive of a meaningful relationship between backpack use or weight and back pain in children and adolescents.

The strength of this review is that we focused on data from prospective studies that investigated schoolbag characteristics and the risk of back pain, yet also included cross-sectional and retrospective studies to capture all possible relevant information on the topic. Data from the latter studies were considered with respect to the extent to which they were concordant with the longitudinal studies. In the event that there is a causal relationship between backpack use and back pain, we expected that cross-sectional studies would consistently report an association between the two variables, but this evidence of itself would be insufficient. Hence, we expected that data from cross-sectional studies could corroborate inference of a causal association, or lack thereof in the longitudinal data. In this study, we also performed a comprehensive search, we registered the protocol and we assessed the risk of bias of the included studies using robust methods. This study has limitations. We only found five prospective studies to include in this review. Since these studies investigated different variables and present results inconsistently, we were unable to pool results. Despite these limitations, the volume of research and the fact that associations show no consistent pattern suggest that any relationship between backpack use and back pain is minimal at best, and research resources aimed at understanding adolescent back pain are better directed elsewhere.

Previous reviews have investigated the association between back pain and schoolbag characteristics (ie, weight, type, method of carrying) in children and adolescents. ${ }^{9} 1315$ 70-73 Although most of these reviews are based on data from cross-sectional studies, their results generally agree with our findings (ie, there appears no clear association between schoolbags characteristics and back pain in children and adolescents). Most of these reviews are narrative reviews or investigated risk factors without considering longitudinal data. Our review extends the findings of previous studies by providing evidence from five prospective longitudinal studies, which show there is little or no association between schoolbag use and back pain.

Schoolbag use does not appear to be an important risk factor for back pain in children and adolescents. However, due to the small number of prospective studies and low methodological quality of the studies included in this review, our findings should be interpreted with caution. There are few longitudinal cohort studies in children and adolescents in the literature, and in most of these cases identifying risk factors for back pain was not the primary aim. Consequently, the choice of exposure variables, measurement instruments and timing of data collection are not optimal to reveal causal relationships. These problems

Table 3 Results from longitudinal studies included in the review.

\begin{tabular}{lllll}
\hline Study & $\mathbf{n}$ & Schoolbag measures & Back pain measures & Finding \\
\hline Negrini et a P $^{22}$ (RCT) & 108 & $\begin{array}{l}\text { \% Body weight } \\
\text { Load carried }\end{array}$ & Back pain episode & $\begin{array}{l}\text { No association } \\
\text { No association }\end{array}$ \\
Jones and Watson ${ }^{23}$ & 933 & $\begin{array}{l}\text { Load carried } \\
\text { Bag design } \\
\text { Carrying method }\end{array}$ & Back pain episode & $\begin{array}{l}\text { No association } \\
\text { No association } \\
\text { No association }\end{array}$ \\
Jones and Macfarlane ${ }^{21}$ & 330 & Difficulty carrying schoolbag & Persistent back pain & Increased risk: RR 2.1, 95\% Cl 1.1 to 4.0 \\
Sjolie & 88 & Schoolbag use & Pain-provoking situations & No association \\
Szpalski & 392 & Perceived weight & Back pain episode & Increased odds: OR 2.2, 95\% Cl 1.0 to 4.8 \\
\hline
\end{tabular}


may explain why systematic reviews in this field do not have strong conclusions.

These findings call into question the various guidelines and statements that endorse specific weight limits for school bags in children and adolescents. ${ }^{13-15}$ It seems that these recommendations are not based on the most reliable evidence on the subject. The findings also have implications for the various professional bodies and clinicians that endorse or recommend specific backpacks. It is important that such endorsement is made on the basis of firm evidence and free of financial conflict.

\section{CONCLUSION}

Based on evidence from five longitudinal studies ( $\mathrm{n}=1851$ children and adolescents) and more than 60 cross-sectional studies, there is no convincing evidence that aspects of schoolbag use increase the risk of back pain. There is some evidence that the perception of heaviness is associated with back pain.

Acknowledgements TPY holds a PhD scholarship from CAPES (Coordination for the Improvement of Higher Education Personnel), Ministry of Education of Brazil. CGM, CMW and SJK's fellowship are funded by Australia's National Health and Medical Research Council. The authors would like to acknowledge Dr Bruno Saragiotto for critical revision of the manuscript and data analysis.

Contributors TPY performed this study as part of her PhD degree, she led the main writing, screening, data extraction and analysis. CGM was her supervisor and contributed with the concept idea and guiding during the study. ACT, CMW and SJK contributed with revision, screening, data extraction and interpretation of the study.

Funding This research received no specific grant from any funding agency in the public, commercial or not-for-profit sectors.

Competing interests None declared.

Patient consent Not required.

Provenance and peer review Not commissioned; externally peer reviewed.

(c) Article author(s) (or their employer(s) unless otherwise stated in the text of the article) 2018. All rights reserved. No commercial use is permitted unless otherwise expressly granted.

\section{REFERENCES}

1 Hoy D, Bain C, Williams G, et al. A systematic review of the global prevalence of low back pain. Arthritis Rheum 2012;64:2028-37.

2 Briggs AM, Smith AJ, Straker LM, et al. Thoracic spine pain in the general population: prevalence, incidence and associated factors in children, adolescents and adults. A systematic review. BMC Musculoskelet Disord 2009;10:77.

3 Kamper SJ, Henschke N, Hestbaek L, et al. Musculoskeletal pain in children and adolescents. Braz J Phys Ther 2016:275-84.

4 Kamper SJ, Yamato TP, Williams CM. The prevalence, risk factors, prognosis and treatment for back pain in children and adolescents: an overview of systematic reviews. Best Pract Res Clin Rheumatol 2016;30:1021-36.

5 Akdag B, Cavlak U, Cimbiz A, et al. Determination of pain intensity risk factors among school children with nonspecific low back pain. Medical Science Monitor 2011;17:PH12-5.

6 Olsen TL, Anderson RL, Dearwater SR, et al. The epidemiology of low back pain in an adolescent population. Am J Public Health 1992;82:606-8.

7 Swain MS, Henschke N, Kamper SJ, et al. An International survey of pain in adolescents. BMC Public Health 2014;14:447.

8 Skoffer B. Low Back pain in 15- to 16-year-old children in relation to school furniture and carrying of the school bag. Spine 2007;32:E713-7.

9 Balagué F, Troussier B, Salminen JJ. Non-specific low back pain in children and adolescents: risk factors. Eur Spine J 1999;8:429-38.

10 Nicolet T, Mannion AF, Heini P, et al. No kidding: low back pain and type of container influence adolescents' perception of load heaviness. Eur Spine J 2014;23:794-9.

11 Malhotra MS, GUPTA JSEN, Sen Gupta J. Carrying of school bags by children. Ergonomics 1965;8:55-60.

12 Wigram J. Why is low back pain common in adolescence? Education and Health 2002;20:36-7.

13 Lindstrom-Hazel $D$. The backpack problem is evident but the solution is less obvious. Work 2009:32:329-38

14 Rateau MR. Use of backpacks in children and adolescents. A potential contributor of back pain. Orthop Nurs 2004;23:101-5.

15 Dockrell S, Simms C, Blake C. Schoolbag weight limit: can it be defined? I Sch Health 2013;83:368-77.
16 Devroey C, Jonkers I, de Becker A, et al. Evaluation of the effect of backpack load and position during standing and walking using biomechanical, physiological and subjective measures. Ergonomics 2007;50:728-42.

17 Mackie HW, Legg SJ. Postural and subjective responses to realistic schoolbag carriage. Ergonomics 2008:51:217-31.

18 Trevelyan FC, Legg SJ. Risk factors associated with back pain in New Zealand school children. Ergonomics 2011;54:257-62.

19 Stroup DF, Berlin JA, Morton SC, et al. Meta-analysis of observational studies in epidemiology: a proposal for reporting. Meta-analysis Of Observational Studies in Epidemiology (MOOSE) group. JAMA 2000;283:2008-12.

20 de Vet HC, Heymans MW, Dunn KM, et al. Episodes of low back pain: a proposal for uniform definitions to be used in research. Spine 2002;27:2409-16.

21 Jones GT, Macfarlane GJ. Predicting persistent low back pain in schoolchildren: a prospective cohort study. Arthritis Rheum 2009;61:1359-66.

22 Negrini S, Politano E, Carabalona R, et al. The backpack load in schoolchildren: clinical and social importance, and efficacy of a community-based educational intervention. A prospective controlled cohort study. Eura Medicophys 2004;40:185-90.

23 Jones GT, Watson KD, Silman AJ, et al. Predictors of low back pain in British schoolchildren: a population-based prospective cohort study. Pediatrics 2003;111:822-8

24 Sjolie AN. Persistence and change in nonspecific low back pain among adolescents: a 3-year prospective study. Spine 2004;29:2452-7.

25 Szpalski M, Gunzburg R, Balagué F, et al. A 2-year prospective longitudinal study on low back pain in primary school children. Eur Spine J 2002;11:459-64.

26 Akdag B, Cavlak U, Cimbiz A, et al. Determination of pain intensity risk factors among school children with nonspecific low back pain. Med Sci Monit 2011;17:PH12-15.

27 Bejia I, Abid N, Ben Salem K, et al. Low back pain in a cohort of 622 Tunisian schoolchildren and adolescents: an epidemiological study. Eur Spine J 2005;14:331-6.

28 Cavlak U, Cimbiz A, Akdag B. Non specific low back pain in a Turkish population based sample of school children: a field survey with analysis of associated factors. The Pain Clinic 2006;18:351-60.

29 Dockrell S, Simms C, Blake C. Schoolbag carriage and schoolbag-related musculoskeletal discomfort among primary school children. Appl Ergon 2015:51:281-90.

30 Gunzburg R, Balagué F, Nordin M, et al. Low back pain in a population of school children. Eur Spine J 1999:8:439-43.

31 Johnson $\mathrm{OE}$, Adeniji OA, Mbada CE, et al. Percent of body weight carried by secondary school students in their bags in a nigerian school. J Musculoskelet Res 2011;14:1250003.

32 Kaspiris A, Grivas TB, Zafiropoulou C, et al. Nonspecific low back pain during childhood: a retrospective epidemiological study of risk factors. I Clin Rheumatol 2010;16:55-60.

33 Korovessis P, Koureas G, Zacharatos S, et al. Backpacks, back pain, sagittal spinal curves and trunk alignment in adolescents: a logistic and multinomial logistic analysis. Spine 2005:30:247-55

34 Korovessis P, Repantis T, Baikousis A. Factors affecting low back pain in adolescents. J Spinal Disord Tech 2010:23:513-20.

35 Kovacs FM, Gestoso M, Gil del Real MT, et al. Risk factors for non-specific low back pain in schoolchildren and their parents: a population based study. Pain 2003;103:259-68

36 Macedo RB, Coelho-e-Silva MJ, Sousa NF, et al. Quality of life, school backpack weight, and nonspecific low back pain in children and adolescents. J Pediatr 2015;91:263-9.

37 Minghelli B, Oliveira R, Nunes C. Non-specific low back pain in adolescents from the south of Portugal: prevalence and associated factors. J Orthop Sci 2014;19:883-92.

38 Murphy S, Buckle P, Stubbs D. A cross-sectional study of self-reported back and neck pain among English schoolchildren and associated physical and psychological risk factors. Appl Ergon 2007;38:797-804.

39 Negrini S, Carabalona R. Backpacks on! Schoolchildren's perceptions of load, associations with back pain and factors determining the load. Spine 2002;27:187-95.

40 Onofrio AC, da Silva MC, Domingues MR, et al. Acute low back pain in high school adolescents in Southern Brazil: prevalence and associated factors. Eur Spine J 2012;21:1234-40

41 Shehab DK, Al-Jarallah KF. Nonspecific low-back pain in Kuwaiti children and adolescents: associated factors. J Adolesc Health 2005;36:32-5.

42 Skoffer B. Low back pain in 15- to 16-year-old children in relation to school furniture and carrying of the school bag. Spine 2007:32:E713-E717.

43 van Gent C, Dols JJ, de Rover CM, et al. The weight of schoolbags and the occurrence of neck, shoulder, and back pain in young adolescents. Spine 2003:28:916-21.

44 Viry P, Creveuil C, Marcelli C. Nonspecific back pain in children. A search for associated factors in 14-year-old schoolchildren. Rev Rhum Engl Ed 1999;66:381-8

45 Watson KD, Papageorgiou AC, Jones GT, et al. Low back pain in schoolchildren: the role of mechanical and psychosocial factors. Arch Dis Child 2003;88:12-17.

46 Whittfield J, Legg SJ, Hedderley DI. Schoolbag weight and musculoskeletal symptoms in New Zealand secondary schools. Appl Ergon 2005;36:193-8.

47 Chiang HY, Jacobs K, Orsmond G. Gender-age environmental associates of middle school students' low back pain. Work 2006;26:197-206. 
48 De Paula AJ, Silva JC, Paschoarelli LC, et al. Backpacks and school children's obesity: challenges for public health and ergonomics. Work 2012;41(Suppl 1):900-6.

49 Noll M, de Avelar IS, Lehnen GC, et al. Back pain prevalence and its associated factors in brazilian athletes from public high schools: a cross-sectional study. PLoS One 2016;11:e0150542.

50 Wirth B, Knecht C, Humphreys K. Spine Day 2012: spinal pain in Swiss school children-epidemiology and risk factors. BMC Pediatr 2013;13:159.

51 Amyra Natasha A, Ahmad Syukri A, Siti Nor Diana MK, et al. The association between backpack use and low back pain among pre-university students: a pilot study. J Taibah Univ Med Sci 2017.

52 Aprile I, Di Stasio E, Vincenzi MT, et al. The relationship between back pain and schoolbag use: a cross-sectional study of 5,318 Italian students. Spine J 2016;16:748-55.

53 Minghelli B, Oliveira R, Nunes C. Postural habits and weight of backpacks of Portuguese adolescents: Are they associated with scoliosis and low back pain? Work 2016;54:197-208.

54 Poursadeghiyan M, Azrah K, Biglari $\mathrm{H}$, et al. The effects of the manner of carrying the bags on musculoskeletal symptoms in school students in the city of Ilam, Iran. Ann Trop Med Public Health 2017;10:600-5.

55 Adegoke BO, Odole AC, Adeyinka AA. Adolescent low back pain among secondary school students in Ibadan, Nigeria. Afr Health Sci 2015;15:429-37.

56 Harreby M, Nygaard B, Jessen T, et al. Risk factors for low back pain in a cohort of 1389 Danish school children: an epidemiologic study. Eur Spine J 1999;8:444-50.

57 Haselgrove C, Straker L, Smith A, et al. Perceived school bag load, duration of carriage, and method of transport to school are associated with spinal pain in adolescents: an observational study. Aust J Physiother 2008;54:193-200.

58 Astfalck RG, O'Sullivan PB, Straker LM, et al. A detailed characterisation of pain, disability, physical and psychological features of a small group of adolescents with non-specific chronic low back pain. Man Ther 2010;15:240-7.

59 Yao W, Mai X, Luo C, et al. A cross-sectional survey of nonspecific low back pain among 2083 schoolchildren in China. Spine 2011;36:1885-90.
60 Grimmer K, Williams M. Gender-age environmental associates of adolescent low back pain. Appl Ergon 2000;31:343-60.

61 Erne C, Elfering A. Low back pain at school: unique risk deriving from unsatisfactory grade in maths and school-type recommendation. Eur Spine J 2011;20:2126-33.

62 Alghadir AH, Gabr SA, Al-Eisa ES. Mechanical factors and vitamin D deficiency in schoolchildren with low back pain: biochemical and cross-sectional survey analysis. J Pain Res 2017;10:855-65.

63 Spiteri K, Busuttil ML, Aquilina S, et al. Schoolbags and back pain in children between 8 and 13 years: a national study. Br J Pain 2017;11:81-6.

64 Troussier B, Davoine P, de Gaudemaris R, et al. Back pain in school children. A study among 1178 pupils. Scand J Rehabil Med 1994;26:143-6.

65 Noll M, Candotti CT, Rosa BN, et al. Back pain prevalence and associated factors in children and adolescents: an epidemiological population study. Rev Saude Publica 2016:50:10.

66 Ayanniyi O, Mbada CE, Muolokwu CA. Prevalence and profile of back pain in Nigerian adolescents. Med Princ Pract 2011;20:368-73.

67 Balagué F, Skovron ML, Nordin M, et al. Low back pain in schoolchildren. A study of familial and psychological factors. Spine 1995;20:1265-70.

68 Pires Sanchez C, Esquivel F, Felipe M, et al. Does the weight of backpacks cause backache in 10-11 year-old children? Acta Pediatrica Espanola 2011;69:325-31.

69 Watson KD, Papageorgiou AC, Jones GT, et al. Low back pain in schoolchildren: occurrence and characteristics. Pain 2002;97:87-92.

70 Cardon G, Balagué F. Low back pain prevention's effects in school children. What is the evidence? Eur Spine J 2004;13:663-79.

71 Hill JJ, Keating JL. Risk factors for the first episode of low back pain in children are infrequently validated across samples and conditions: a systematic review. $J$ Physiother 2010;56:237-44.

72 Trevelyan FC, Legg SJ. Back pain in school children - where to from here? Appl Ergon 2006;37:45-54.

73 Smith D, Leggat P. Back pain in the young: a review of studies conducted among school children and university students. Current Pediatric Reviews 2007;3:69-77. 